\title{
TRANSFERÊNCIA DE MASSA E SECAGEM EM LEITOS VIBROFLUIDIZADOS - UMA REVISÃO
}

\section{KIL J. PARK ${ }^{1}$, FERNANDO P. R. BROD ${ }^{2}$, RAFAEL A. DE OLIVEIRA ${ }^{3}$}

\begin{abstract}
RESUMO: O desenvolvimento de tecnologias de processamento e equipamentos requer a utilização de novos métodos e melhor qualidade do produto processado. Dentro do processo de secagem contínua, a utilização de equipamentos que promovem incremento nos coeficientes de transferência, é a de maior interesse. O uso de energia vibracional tem sido recomendado para materiais dispersos. Assim, uma revisão da literatura sobre a transferência de massa e a secagem em leitos vibrofluidizados foi realizada, envolvendo resultados experimentais e modelagem matemática.
\end{abstract}

PALAVRAS-CHAVE: taxa de secagem, parâmetro vibracional, transferência de massa.

\section{MASS TRANSFER AND DRYING IN VIBRO-FLUIDIZED BEDS - A REVIEW}

\begin{abstract}
Development of processing technology and equipments requires new methods and better quality of the processed product. In the continuous drying process, utilization of equipments that promotes an increment in the transfer coefficients becomes of the major interest. The use of vibrational energy has been recommended to the dispersed materials. Such method is based on the use of vibrational energy applied to disperse media. Thus, a literature review on the mass transfer and drying in vibro-fluidized beds was carried out, showing experimental results and mathematical modeling.
\end{abstract}

KEYWORDS: drying rate, vibration parameter, mass transfer.

\section{INTRODUÇÃO}

De acordo com GUPTA \& MUJUMDAR (1980 a, b), que apresentaram uma das primeiras revisões sobre leitos vibrofluidizados, a primeira aplicação comercial de um secador vibrofluidizado (SVF) foi reportada nos anos de 1938 por Allis-Chalmers, que operou uma unidade para a secagem de molibdênio mineral. Atualmente, alguns exemplos das suas aplicações podem ser encontrados na aglomeração de leite em pó, secagem de fertilizantes, açúcar, raspas de polímeros, sais inorgânicos, produtos farmacêuticos, fibras de asbestos, etc. Os autores ainda salientaram que o SVF é objeto de muita pesquisa e desenvolvimento, principalmente na antiga União Soviética, com $75 \%$ das publicações em russo, $15 \%$ em polonês, romeno e japonês, e com menos de $10 \%$ em inglês, dados de 1980. STRUMILLO \& PAKOWSKI (1980) também apresentaram no livro Drying '80 uma extensa revisão da literatura. Em 1983, no livro Advances in Drying, PAKOWSKI et al. (1984) escreveram um capítulo inteiro dedicado aos leitos vibrofluidizados, com mais de 130 referências. ERDÉSZ \& MUJUMDAR (1987) apresentaram mais de 230 bibliografias referentes às aplicações da vibração em processamento de partículas das duas últimas décadas, com material em russo, húngaro, checo, polonês, japonês e inglês. Revisões sobre LVF também foram feitas por ERDÉSZ (1990). Um resumo em inglês de uma tese de doutorado em russo com estudos sobre a hidrodinâmica, reologia e transferência de calor e massa foi apresentado por RYZHKOV (1992).

\footnotetext{
${ }^{1}$ Eng $^{\mathrm{o}}$ de Alimentos, Professor Titular, FEAGRI/UNICAMP, Caixa Postal 6011, Campinas - SP, Fone/Fax: (0XX19) 3788.1076, kil@agr.unicamp.br

${ }^{2}$ Eng ${ }^{0}$ Agrícola, Doutor em Engenharia Agrícola, FEAGRI/UNICAMP, fernando.brod@ @epler.com.br

${ }^{3}$ Eng $^{0}$ Agrícola, Doutorando em Tecnologia Pós-Colheita. FEAGRI/UNICAMP, augustus@ agr.unicamp.br

Recebido pelo Conselho Editorial em: 16-4-2004
}

Aprovado pelo Conselho Editorial em: 5-9-2006 
FINZER \& KIECKBUSCH (1992) também fizeram uma revisão bastante detalhada da secagem em sistemas de vibração.

Algumas teses ou dissertações sobre o assunto, publicadas no Brasil, também foram encontradas, principalmente na Universidade Federal de São Carlos (Departamento de Engenharia Química) e Universidade Estadual de Campinas (Faculdade de Engenharia de Alimentos e Faculdade de Engenharia Agrícola).

A procura pelo termo vibro-fluidized em sistemas de busca pela Internet resulta em mais de 160 páginas e pelo termo vibrofluidized em mais de 100, confirmando a grande quantidade de informações referentes a esse tema.

A secagem vibrofluidizada é utilizada para materiais termolábeis, que requerem tempos de residência curtos, altas taxas de secagem e baixas temperaturas de secagem, tais como: materiais granulares, pastas e pós, como materiais farmacêuticos, biológicos e alimentares (BORDE et al., 1996; HAN et al., 1991).

Sabe-se, também, que a vibração do leito, sua inclinação e o insuflamento de ar são características importantes para a determinação do tempo de residência dos materiais durante o processo de secagem (MROWIEC \& CIESIELCZYK, 1977).

\section{REVISÃO}

\section{Transferência de massa em leitos vibrofluidizados}

A transferência de massa em leitos vibrofluidizados (LVF) tem sido muito menos estudada do que a transferência de calor. Somente poucas observações foram realizadas e pouca informação é disponível na influência da vibração na transferência de massa (FINZER \& KIECKBUSCH, 1992; PAKOWSKI et al., 1984; STRUMILLO \& PAKOWSKI, 1980).

WONG et al. (1978), citados por FINZER \& KIECKBUSCH (1992), estudaram a transferência de massa usando cilindros de naftaleno vibrados, imersos em uma corrente de ar. Concluíram que, para baixos números de Reynolds, o aumento da aceleração vibracional aumenta a transferência de massa, enquanto, ao operar com altos números de Reynolds, ocorre o inverso.

Utilizando a analogia de Colburn de transferência de massa e calor, CHOC (1967), citado por PAKOWSKI et al. (1984), determinou a seguinte equação:

$$
\frac{\mathrm{h}_{\text {vib }}}{\mathrm{h}}=\frac{\left(\mathrm{k}_{\mathrm{y}}\right)_{\mathrm{vib}}}{\mathrm{k}_{\mathrm{y}}}=14,0\left(\frac{\mathrm{Af}}{\mathrm{u}_{\mathrm{g}}}\right)^{0,65}
$$

Já MUSHTAYEV et al. (1974), citados por PAKOWSKI et al. (1984), avaliaram o processo de secagem de partículas de um tipo de PVC, resultando na seguinte expressão para a transferência de massa:

$$
\mathrm{k}_{\mathrm{y}}=5,0310^{-5} \frac{\mathrm{d}_{\mathrm{L}} \mathrm{u}_{\mathrm{g}}^{0,4}}{(1-\varepsilon)^{0,4} \mathrm{v}_{\mathrm{g}}^{0,4} \mathrm{~d}_{\mathrm{p}}^{0,6}} \frac{\mathrm{A} \omega^{2}}{\mathrm{~g}}
$$

Utilizando um SVF de seção transversal de 0,40 m de largura por 0,10 $\mathrm{m}$ de comprimento e 0,30 m de altura, GARIM \& FREIRE (1994a) estudaram a transferência de massa de um sistema ar-naftaleno $\left(\mathrm{d}_{\mathrm{p}}=0,025 \mathrm{~m}\right)$. As variáveis independentes envolvidas foram: velocidade superficial do ar, amplitude e frequiência de vibração (sozinhas e juntas no adimensional de vibração, $\Gamma$ ) e $o$ coeficiente de transferência de massa como variável resposta. As condições experimentais foram estabelecidas mediante planejamento fatorial, que possibilitou a obtenção de modelo estatístico quadrático que representou os dados experimentais com coeficiente de correlação de 0,888 , utilizando a amplitude e a freqüência de vibração, e de 0,801 , utilizando o adimensional de vibração. Os modelos ajustados foram: 


$$
\begin{aligned}
& k_{y} \rho=-1,79+0,95 \mathrm{~A}+1,8210^{-3} \mathrm{f}+10,75 \mathrm{u}_{\mathrm{g}}-1,54 \mathrm{~A} \mathrm{u}_{\mathrm{g}}+2,7810^{-2} \mathrm{~A}^{2} \\
& \mathrm{k}_{\mathrm{y}} \rho=2,01+4,15 \Gamma-4,58 \Gamma \mathrm{u}_{\mathrm{g}}-1,38 \Gamma^{2}+7,65 \mathrm{u}_{\mathrm{g}}{ }^{2}
\end{aligned}
$$

Observou-se que, para baixas velocidades, o $\Gamma$ tem influência mais significativa no aumento do coeficiente. Quando a velocidade aumenta, o coeficiente de transferência de massa tende a crescer, mas a influência do parâmetro vibracional é menor devido, acredita-se, à formação de bolhas no leito, favorecendo a desuniformidade da distribuição do ar.

GARIM \& FREIRE (1994b), em outro trabalho com atrição do mesmo sistema, determinaram o coeficiente de transferência de massa a várias temperaturas em condições fluidodinâmicas semelhantes. Concluíram que o aumento do coeficiente com o decréscimo da temperatura indica a influência da atrição no coeficiente, conforme indicado na eq.(5):

$$
\mathrm{k}_{\mathrm{y}} \rho=3,67+0,77 \Gamma-0,04 \mathrm{~T}+7,38 \mathrm{u}_{\mathrm{g}}{ }^{2}
$$

CANELLAS NETO \& FREIRE (2000) estudaram a transferência de massa em leito vibrofluidizado utilizando a técnica de sublimação do naftaleno. Concluíram que os parâmetros vibracionais, a velocidade incipiente e o atrito entre as partículas esféricas de vidro utilizadas e o molde de naftaleno influenciam nos valores do coeficiente de transferência de massa.

BORDE et al. (1997) utilizaram as seguintes equações para predizer a transferência de massa, nas quais utilizam o conceito de massa crítica que corresponde à massa evaporada no ponto crítico da secagem:

$$
\mathrm{Sh}=\frac{\mathrm{k}_{\mathrm{y}} \mathrm{d}_{\mathrm{p}}}{\rho \mathrm{D}}=\frac{2+0,6 \mathrm{Re}^{0,5} \mathrm{Sc}^{0,333}}{(1+\mathrm{Sp})^{0,7}}
$$

E a massa de água evaporada durante a secagem:

$$
\begin{aligned}
& \mathrm{m}_{\mathrm{ev}, 1}=\mathrm{k}_{\mathrm{y}} \mathrm{t}_{1} \mathrm{~S} \\
& \mathrm{~m}_{\mathrm{ev}, 2}=\mathrm{m}_{\mathrm{cr}}\left[1-\frac{\mathrm{m}_{\mathrm{cr}}}{\mathrm{m}_{\mathrm{cr}}-\mathrm{k}_{\mathrm{y}} \mathrm{t}_{2}}\right]^{\frac{1}{\mathrm{cf}-1}}
\end{aligned}
$$

SANZ et al. (1977) propuseram a seguinte equação empírica para a transferência de massa em um leito vibrofluidizado de farelo de arroz:

$$
\mathrm{k}_{\mathrm{y}} \mathrm{s}=14,43 \mathrm{~d}_{\mathrm{c}}^{-0,8} \operatorname{Re}^{0,94}
$$

E a equação para a velocidade média de secagem, no período de taxa constante, assume a seguinte forma:

$$
\mathrm{k}_{\mathrm{y}} \mathrm{s}=\frac{\mathrm{dX}}{\mathrm{dt}}{ }_{\mathrm{cte}} \frac{\rho_{\mathrm{s}}}{\left(\mathrm{X}_{\mathrm{int}}-\mathrm{X}\right)_{\mathrm{ml}}}
$$

Os autores relacionaram a transferência de calor com a transferência de massa, utilizando a relação de Lewis:

$$
\frac{\mathrm{h}_{\mathrm{gp}} \mathrm{s}}{\mathrm{k}_{\mathrm{y}} \mathrm{s}}=0,97
$$

Valor bem próximo do proposto por Lewis para o sistema ar-água $=0,945$.

\section{Secagem em leitos vibrofluidizados}

GUPTA \& MUJUMDAR (1980 a) relataram que os LVF encontram sua maior aplicação na secagem de materiais pastosos, granulares e pós, dos quais se podem exemplificar: sal comum, acetato de polyvinil, pastas antibióticas, concentrados de molibdênio, grânulos farmacêuticos, 
minério de ferro, cafeína, cascalho, raspas de madeira, caseinato de sódio, ácido hidróxido de benzóico, óxido de alumínio, nitrato de sódio, bicarbonato de sódio, óxido de cálcio, etc.

A presença de um ponto ótimo nos parâmetros de vibração, o qual proporciona elevada taxa de secagem, é a mais marcante característica de LVF. Assim, a procura desse ponto é objeto de estudo da maioria das pesquisas.

MUJUMDAR (1991) explica que uma clara tendência atualmente é a combinação de dois diferentes tipos de secadores quando as características de secagem do material permitem tal combinação. No passado, somente um tipo de secador era selecionado. Por exemplo, a combinação de um secador flash (ideal para remover a umidade superficial de sólidos particulados em alguns segundos) seguido por um pequeno secador de leito fluidizado, com maior tempo de residência para remover o conteúdo de umidade interno. O segundo secador poderia ser um secador de leito vibrátil ou um leito fluidizado com aquecimento indireto, dependendo das características do produto. $\mathrm{O}$ autor também espera que os sistemas de secagem incluam cada vez mais dois ou mais tipos dos secadores se as características da cinética de secagem e do produto justificarem. Tais sistemas são inerentemente mais flexíveis e podem ser justificados no âmbito da flexibilidade em processar e em manufaturar. O dimensionamento, o projeto e a otimização do sistema, entretanto, serão mais complexos.

Aumento da taxa de secagem pode ocorrer quando se agita um leito de secagem sob ação vibracional, dependendo das condições de operação, de parâmetros geométricos e das características físicas do leito. A influência da vibração sobre a taxa de secagem depende da faixa de velocidade do ar $\left(u_{\mathrm{g}}\right)$. Para $\mathrm{u}_{\mathrm{g}}<\mathrm{u}_{\mathrm{mf}}$, a influência é maior do que quando $\mathrm{u}_{\mathrm{g}}>\mathrm{u}_{\mathrm{mf}}$. Para $A \omega^{2} / \mathrm{g}>>$ 1, o aumento de $u_{\mathrm{g}}$ acima de $\mathrm{u}_{\mathrm{mf}}$ pode reduzir a taxa de secagem (PAKOWSKI et al., 1984).

Quando ocorre aumento da taxa de secagem, a mistura das partículas é mais intensa e ocorre desagregação de aglomerados (ERDÉSZ \& MUJUMDAR, 1987). Os processos de transferência de calor e massa ocorrem em maior intensidade quando a operação é realizada em regime de ressonância (ERDÉSZ, 1990).

Embora exista grande número de configurações de SVF, a configuração mais popular é aquela na qual o fundo do secador é perfurado e o vetor da vibração é ligeiramente inclinado para promover o transporte dos sólidos. A utilização de molas adequadas possibilita a redução do consumo de energia; além disso, a redução da vazão de ar (devido à vibração) reduz também o investimento inicial do sistema (RINGER \& MUJUMDAR, 1983-84).

HASATANI et al. (1991), apresentando as vantagens de um leito fluidizado comum (estrutura simples, facilidade de operações em escala contínua, aumento da transferência de calor e massa entre as partículas e o ar quente, etc.), juntamente com as desvantagens (aumento do consumo de energia devido ao aumento do fluxo de ar e a dificuldade de fluidizar partículas aglomeradas), sugerem secador vibrofluidizado que supere essas desvantagens desde que o secador não seja só usado para fluidizar partículas a baixas velocidades do ar, mas também para quebrar os aglomerados.

O uso de vibração em secadores apresenta outras vantagens sobre os leitos de jorro ou fluidizados convencionais, como:

- O ar pode escoar a velocidades muito baixas que, por si sós, não poderiam movimentar o leito, ocorrendo o efeito redutor da vibração sobre a velocidade mínima de fluidização (KUDRA, 1992; FINZER \& KIECKBUSCH, 1992);

- Menor perda de carga e facilidade de atingir o regime plug-flow (DONG et al., 1991);

- A movimentação do leito devido à vibração reduz a resistência para a transferência de calor e massa, resultando em um aumento da umidade removida durante o período de taxa constante (STRUMILLO \& PAKOWSKI, 1980); 
- A vibração possibilita melhor distribuição do conteúdo de umidade das partículas no leito e a utilização de temperaturas menores do ar devido ao aumento da transferência de calor e massa (HASATANI et al., 1991);

- A distribuição do tempo de residência das partículas é mais uniforme, e a degradação térmica em regiões estagnadas pode ser evitada, além de resultar em tempos de secagem menores (STRUMILLO \& PAKOWSKI, 1980);

- Por meio da regulagem da amplitude e da freqüência, consegue-se fácil controle do tempo de residência (HAN et al., 1991);

- A vibração ajuda a manter melhores condições de secagem, no período de secagem, à taxa decrescente (STRUMILLO \& PAKOWSKI, 1980);

- O movimento do material por meio do secador é mais suave, o que reduz o atrito entre as partículas, sendo, portanto, muito adequado ao tratamento de materiais frágeis (DANIELSEN \& HOVMAND, 1980; SHILTON \& NIRANJAN, 1993);

- O secador serve também de transportador dos sólidos (DANIELSEN \& HOVMAND, 1980);

- Apesar da vibração, ocorre menor consumo de potência total (DANIELSEN \& HOVMAND, 1980), e, devido às menores massas vibratórias, as forças inerciais são reduzidas, ocorrendo economia de energia elétrica (MUJUMDAR \& ERDÈSZ, 1988);

- O uso da vibração também é uma solução para o caso em que o material possui distribuição que abrange toda a largura do leito; o leito é feito de material corrosivo ou existem caminhos preferenciais (by-passed) no leito de secagem (BAHU, 1994);

- A fluidização pode ser alcançada para materiais coesos, aderentes e pastas, nos quais a simples fluidização seria difícil de atingir (MUJUMDAR \& ERDĖSZ, 1988).

ZAITSEV et al. (1977), citados por GUPTA \& MUJUMDAR (1980 a), reportaram aumento de 1,5 a 2,5 vezes na taxa de secagem de um LVF comparado com leitos fluidizados convencionais. Já OSINISKI et al. (1969), citados por GUPTA \& MUJUMDAR (1980 a), encontraram aumento de até seis vezes na taxa de secagem. Observações similares também são reportadas por ZELEPUG et al. (1975), citados por GUPTA \& MUJUMDAR (1980 a), que propuseram a seguinte equação para a taxa de secagem de cascalho:

$$
\frac{\mathrm{dX}}{\mathrm{dt}}=\left(0,8 \frac{\mathrm{A} \omega^{2}}{\mathrm{~g}}-2,3\right)\left(0,02 \mathrm{~T}_{\mathrm{g}}-6,16\right)(1,0-8,9 \mathrm{H})\left(1,9 \mathrm{u}_{\mathrm{g}}-0,65\right)
$$

Os leitos vibratórios são utilizados como eficientes granuladores-secadores, geralmente após um spray-dryer para que o produto tenha características de instantaneidade ao ser reconstituído. Os leitos vibrofluidizados são também utilizados em plantas industriais de aglomeração para a secagem de materiais úmidos que deixam o aglomerador.

ERDÉSZ \& ORMÓS (1986) estudaram a granulação em um LVF de partículas sólidas. Os parâmetros analisados foram os seguintes: diâmetro médio das partículas, distribuição de tamanhos, quantidade de produto fracionado e rigidez dos grânulos.

GUPTA et al. (1980), citados por HOVMAND (1987), concluíram que a vibração não muda consideravelmente o conteúdo crítico de umidade das partículas, e o mecanismo de secagem no período de taxa decrescente não é também muito afetado. No período de secagem à taxa constante, a vibração aumenta a taxa de secagem para valores de $\mathrm{A} \omega^{2} / \mathrm{g}>1$.

JINESCU \& BALABAN (1982) estudaram a cinética de secagem do polímero estirênico em leito vibrofluidizado vertical. Baseado em experimento fatorial, concluíram que o LVF permitiu a secagem desse polímero com altos conteúdos de umidade e obtiveram a seguinte correlação empírica para a taxa de secagem: 


$$
\frac{\mathrm{dX}}{\mathrm{dt}}=0,341 \mathrm{X}_{0}^{0,0325} \mathrm{~T}^{0,01} \text { if }^{-0,0285}\left(\frac{\mathrm{H}}{\mathrm{d}_{\mathrm{L}}}\right)^{-0,022}\left(\frac{\mathrm{A} \omega^{2}}{\mathrm{~g}}\right)^{0,0225} \mathrm{~d}_{\mathrm{mv}}^{0,0235} \rho^{0,0285}
$$

MUJUMDAR \& ERDÉSZ (1988) descreveram que existem três métodos típicos de secagem em SVF em escala industrial:

- Secagem e resfriamento de produtos em leitos contínuos com ar pré-aquecido;

- Secagem de materiais termossensíveis em SVF de contato (ou radiativos), e

- Secagem de materiais pastosos em SVF de coluna, utilizando leito inerte.

BORDE et al. (1997) concluíram que, para a secagem de materiais termolábeis, a intensidade vibracional é o parâmetro mais importante na taxa de secagem. Aumento na $\Gamma$ de 3 para 7 reduz o tempo de secagem em $45 \%$.

Já SZALAY et al. (1995), utilizando duas configurações de secadores vibrofluidizados, uma horizontal (tipo canal) e outra vertical (tipo espiral), propuseram um algoritmo para o projeto de equipamentos vibráteis para processamento de produtos. Para tanto, é necessário sincronizar o tempo de residência das partículas na área de processamento com a duração da secagem. $\mathrm{O}$ tempo de secagem depende das propriedades físicas do material processado, dos parâmetros térmicos do leito e dos parâmetros operacionais. O tempo de residência depende das propriedades mecânicas das partículas, da intensidade de transporte e dos parâmetros geométricos do equipamento. Assim, para a otimização do processo e o ótimo projeto de equipamentos vibráteis, tem-se de controlar o principal parâmetro que governa o processamento desses equipamentos: a intensidade da vibração.

DONG et al. (1991), utilizando sílica gel, ácido cítrico e milho, comprovaram o efeito redutor da vibração na taxa de secagem durante o período de secagem à taxa decrescente. Na amplitude ótima dos parâmetros de vibração, o conteúdo de umidade crítica decresceu significantemente quando comparado à secagem em leitos fluidizados convencionais.

A razão para o decréscimo do conteúdo crítico de umidade é devida à vibração quebrar o aglomerado de partículas e resultar em melhor fluidização e aumento da área superficial para a secagem. Outro motivo se baseia no fato de que a vibração pode destruir parcialmente a capilaridade da água entre os poros e a matriz sólida, enquanto a viscosidade efetiva da água é reduzida devido à vibração.

PAN et al. (1995), nesse mesmo secador, secaram uma suspensão de bactérias fotossintéticas em leito contínuo e em batelada de partículas porosas inertes. Essas bactérias são importantes na decomposição de compostos orgânicos, contribuindo assim para o controle da poluição ambiental. Infelizmente, essas bactérias in natura não podem ser armazenadas por um período de tempo longo, necessitando, portanto, de um processo de estocagem que garanta a eficiência das mesmas. Os métodos utilizados, em princípio, foram a secagem a vácuo e a liofilização, que tinham o inconveniente do alto custo. Assim, a secagem vibrofluidizada foi utilizada e mostrou-se eficiente na secagem de materiais biológicos líquidos absorvidos em partículas porosas inertes.

Em outro trabalho, PAN et al. (1997 b) compararam a secagem de Moyu (planta herbácea chinesa) no SVF anterior (laboratorial), em um SVF horizontal, em escala industrial e em um secador de bandejas. A extrapolação dos dados laboratoriais para uma escala industrial foi comprovada, e um secador de três estágios foi sugerido.

PAN et al. (1997 a) mostraram que o secador vibrofluidizado (SVF) vem se tornando uma técnica bastante competitiva atualmente, pois, além de oferecer operação contínua sob pressão atmosférica, tempos de secagem menores e menor consumo de energia, mantém ou melhora o sabor e preserva melhor os nutrientes dos alimentos em comparação à secagem liofilizada (que tem a desvantagem do alto custo). Os autores utilizaram cenouras cortadas em cubos para verificar o efeito da adição de um estágio de repouso (tempering period). Comprovaram o efeito redutor do tempering no tempo total de secagem e no consumo de energia total, além do SVF oferecer tempo 
de secagem muito menor comparado a um secador de bandejas. Já PAN et al. (1999 a) testaram o uso do estágio de repouso na cinética de degradação do $\beta$-caroteno em cenouras cortadas em cubos. Desenvolveram um modelo matemático que prevê essa degradação e concluíram que o uso do estágio de repouso diminui a degradação do $\beta$-caroteno assim como reduz o tempo de secagem.

Esse estágio de repouso também foi testado por PAN et al. (1999 b) na secagem de fatias de abobrinha, com o objetivo de encontrar condições ótimas de secagem e a redução da degradação do $\beta$-caroteno. Concluíram que a secagem intermitente com estágio de repouso reduz a degradação do $\beta$-caroteno, aumenta a capacidade de reidratação, diminui o tempo de secagem e reduz o consumo de energia no processo de secagem.

HASATANI et al. (1985) propuseram um modelo matemático e o resolveram numericamente para a taxa de secagem de partículas granulares em leito fluidizado inclinado vertical de três estágios. Concluíram que a vibração aumentou a taxa de secagem, e o seu efeito pode ser considerado como equivalente a um aumento na velocidade do ar.

$\mathrm{O}$ coeficiente de transferência de massa $\left(\mathrm{k}_{\mathrm{y}}\right)$ foi estimado com base na relação de Lewis entre transferência de calor e massa. O valor da velocidade linear das partículas foi calculado segundo a equação empírica descrita abaixo:

$$
\frac{\mathrm{u}_{\mathrm{s}}}{\mathrm{u}_{\mathrm{g}}}=2,7510^{-3}\left(\frac{\mathrm{d}_{\mathrm{p}}^{2} \mathrm{u}_{\mathrm{g}} \rho_{\mathrm{s}}}{\dot{\mathrm{m}}_{\mathrm{s}}}\right)^{-0,8}\left(\frac{\left(\mathrm{u}_{\mathrm{g}}-\mathrm{u}_{\mathrm{g}, \mathrm{mf}}\right) \mathrm{d}_{\mathrm{p}} \rho_{\mathrm{g}}}{\mu_{\mathrm{g}}}\right)^{0.575}
$$

Um novo parâmetro característico, referido com uma velocidade aparente do ar, $\mathrm{u}_{\mathrm{g}}{ }^{*}$, foi introduzido e correlacionado da seguinte forma:

$$
\begin{array}{ll}
\frac{\mathrm{u}_{\mathrm{g}}+\mathrm{u}_{\mathrm{g}}^{*}}{\mathrm{u}_{\mathrm{g}}}=1,0 & \Gamma<3,5 \\
\frac{\mathrm{u}_{\mathrm{g}}+\mathrm{u}_{\mathrm{g}}^{*}}{\mathrm{u}_{\mathrm{g}}}=0,285 \Gamma & 3,5<\Gamma<15
\end{array}
$$

em que,

$$
\Gamma=\left(\frac{\mathrm{d}_{\mathrm{p}}^{2} \mathrm{u}_{\mathrm{g}} \rho_{\mathrm{s}}}{\dot{\mathrm{m}}_{\mathrm{s}}}\right)^{0,3}\left(\frac{\rho_{\mathrm{g}} \mathrm{u}_{\mathrm{g}}^{2}}{\left(\rho_{\mathrm{s}}-\rho_{\mathrm{g}}\right) \mathrm{d}_{\mathrm{p}} \mathrm{g}}\right)^{-0,4}\left(\frac{\mathrm{A} \omega^{2}}{2 \mathrm{~g} \operatorname{sen} \varphi}\right)^{0.42}
$$

HASATANI et al. (1991) sugeriram um SVF inclinado para melhor mistura das partículas na direção do comprimento do secador, além de oferecer as vantagens conhecidas de um secador vibrofluidizado (estrutura simples, fácil operação contínua, transferência de calor e massa entre as partículas aumentada, redução da velocidade de fluidização, não-formação de aglomerados e homogeneidade da umidade do produto). Uma fonte de energia radiativa foi utilizada como fonte extra de energia térmica e foi comprovado o aumento da taxa de secagem com esse tipo de aparato.

Os autores determinaram, a partir de um balanço de massa e de energia no secador, dado por:

$$
\begin{aligned}
& \mathrm{u}_{\mathrm{p}}\left(\mathrm{c}_{\mathrm{p}}+\mathrm{c}_{\mathrm{pH}_{2} \mathrm{O}} \mathrm{X}\right) \frac{\mathrm{dT} \mathrm{T}_{\mathrm{p}}}{\mathrm{dy}}=\mathrm{h}_{\mathrm{p}} \operatorname{Sm} \Delta \mathrm{T}_{\mathrm{m}}+\lambda \mathrm{u}_{\mathrm{p}} \frac{\mathrm{dX}}{\mathrm{dy}}+\mathrm{q}_{\mathrm{r}} \frac{\mathrm{u}_{\mathrm{p}} \mathrm{L}}{\dot{\mathrm{m}}} \\
& -\mathrm{u}_{\mathrm{p}} \frac{\mathrm{dX}}{\mathrm{dy}}=\mathrm{k}_{\mathrm{y}} \operatorname{Sm} \delta \Delta \mathrm{W}_{\mathrm{m}}
\end{aligned}
$$

em que,

$$
\delta=\left\{\begin{array}{lc}
1,0 & X_{\text {cr }} \leq \mathrm{X} \\
\left(\mathrm{X}-\mathrm{X}_{\mathrm{eq}}\right) /\left(\mathrm{X}_{\mathrm{cr}}-\mathrm{X}_{\mathrm{eq}}\right) & \mathrm{X}_{\mathrm{eq}} \leq \mathrm{X} \leq \mathrm{X}_{\mathrm{cr}}
\end{array}\right.
$$


Utilizando um SVF vertical a batelada, CARDOSO \& KIECKBUSCH (1998) estudaram a secagem de fatias de banana pré-tratadas a altas temperaturas $\left(130\right.$ e $\left.150{ }^{\circ} \mathrm{C}\right)$ por um curto tempo (13 e $8 \mathrm{~min}$ ). Obtiveram banana desidratada crocante, de menor densidade e cor mais duradoura, comparada com o secador estático. A vibração teve maior influência na expansão do leito, não obtendo influências significativas nos outros parâmetros. As condições operacionais ótimas foram: temperatura de $150{ }^{\circ} \mathrm{C}$, velocidade do ar de $1,0 \mathrm{~m} \mathrm{~s}^{-1}$, tempo de exposição de 8 min e frequiência de vibração de $10,1 \mathrm{~Hz}$.

SANZ et al. (1977) determinaram o tempo total de secagem considerando também o período decrescente:

$$
\mathrm{t}=\frac{\mathrm{X}_{0}-\mathrm{X}_{\mathrm{cr}}}{\frac{\mathrm{dX}}{\mathrm{dt}}_{\mathrm{cte}}}+\frac{546,4\left(\mathrm{~d}_{\mathrm{c}} / \dot{\mathrm{m}}_{\mathrm{g}}\right)}{\mathrm{T}} \frac{\left(\mathrm{X}_{\mathrm{cr}}-\mathrm{X}_{\mathrm{eq}}\right)}{\left(\mathrm{X}_{\mathrm{f}}-\mathrm{X}_{\mathrm{eq}}\right)}
$$

NILSSON \& WIMMERSTEDT (1987) utilizaram um SVF horizontal com diâmetro de 0,1m para desenvolver dois modelos de fluxo longitudinal baseados nas isotermas de sorção, cinética de secagem e nos dados de transporte do material. Quatro diferentes materiais foram utilizados nos experimentos: areia e pentaeritrol (não-higroscópicos), sódio formato (higroscópico) e apatita. O secador foi vibrado, e os níveis de vibração foram encontrados para aumentar a mistura de sólidos e para reduzir o fenômeno de channelling (canais preferenciais) no leito úmido. Os autores concluíram que ambos os modelos de fluxo de sólidos (dispersão e plug flow puro) se ajustaram muito bem aos dados experimentais, com a predição praticamente igual do comprimento do leito, suficiente para atingir a umidade de saída do produto.

Os valores do coeficiente de dispersão variaram de 0,0005 a $0,002 \mathrm{~m}^{2} \mathrm{~s}^{-1}$ para uma amplitude fixa de $2 \mathrm{~mm}$ e para vazão de sólidos de 0,049 a $0,16 \mathrm{~kg} \mathrm{~s}^{-1}$.

SHAH \& GOYEL (1995) desenvolveram um SVF para a secagem de chá.

Em relação ao uso de secadores de bandejas vibradas, têm-se alguns artigos sobre o assunto:

MENEZES et al. (1995) desenvolveram o secador de bandejas vibradas, com enfoque no projeto e confecção do sistema de vibração, calculando qual seria a mola mais adequada para o equipamento. Além disso, realizaram alguns testes para determinar a distribuição do tempo de residência de grãos de café dentro do secador. Concluíram que, aumentando o adimensional de vibração, a zona de não-escoamento diminui.

MENEZES et al. (1996 a) estudaram a secagem de café no secador de bandejas vibradas sem reaquecimento interno do ar de secagem (operação não-isotérmica) e com reaquecimento interno do ar de secagem (operação isotérmica).

Os mesmos autores, em outro artigo (MENEZES et al., 1996 b), estudaram a dinâmica do leito utilizando os modelos de escoamento de Dispersão de Taylor e de Dispersão Livre, originalmente desenvolvidos para os estudos do escoamento de gases e líquidos.

BANZATTO et al. (2000), utilizando secador de bandejas vibradas para café, concluíram que a vibração ajuda no escoamento do leito, devido à maior contração dos frutos e da diminuição da pegajosidade.

HAN et al. (1991) comprovaram o efeito significativo da intensidade da vibração na taxa de secagem. A velocidade do ar apresentou pouca influência na taxa de secagem. Aumento na altura do leito acarretou em diminuição da taxa de secagem, e o aumento da temperatura do ar resultou em aumento na taxa de secagem.

Em relação a bolhas, ROWE (1971) afirmou que a vibração pode reduzir a velocidade das bolhas consideravelmente, assim como a fração sombra das bolhas. Isso é, infelizmente, uma limitação experimental. A vibração também age como redutor de atrito estático nas paredes do leito 
fluidizado. Já ECCLES \& MUJUMDAR (1997) relataram que o principal efeito sobre a formação de bolhas é o ponto de ressonância, onde as bolhas alcançam diâmetro máximo ao mesmo tempo em que a velocidade diminui e a freqüência é mínima. Assim, o uso da vibração resulta em estabilização das bolhas, sendo um parâmetro de melhor controle do que a vazão de ar. ERDÉSZ (1990) também afirmou que a presença de bolhas influencia significantemente na eficiência na transferência de calor e massa, e que a sua formação pode ser controlada pelos parâmetros vibracionais (amplitude e freqüência).

FINZER (1984) e FINZER \& KIECKBUSCH (1992) estudaram o comportamento de secagem em batelada de fatias de cebola em leito vibrofluidizado, comparando com o leito estático, obtendo várias conclusões: a vibração reduz o tempo de secagem; mesmo com a utilização da vibração adicional, o consumo de energia foi menor; a cebola seca no leito vibrofluidizado apresentou maior taxa de reidratação, e não existiu diferença significativa na análise sensorial da cebola seca no SVF.

Esse mesmo secador também foi utilizado por NOVY \& KIECKBUSCH (1987) para a secagem de leite desnatado reconstituído em leito de material inerte de alta densidade. Foram testados os efeitos da temperatura do ar, concentração do produto e o tamanho das esferas, sendo esse último o parâmetro que apresentou maior influência na taxa de obtenção do pó.

Na Iugoslávia, STAKIĆ (1995), com sua tese de doutorado, estudou a secagem de materiais pulverulentos e finos por meio da simulação numérica de modelo matemático de transferência simultânea de calor e massa em regime não-permamente entre as fases gás-partícula.

MORENO et al. (2000) estudaram a secagem de serragem em um SVF vertical. A temperatura de secagem mostrou-se como o parâmetro de maior influência na cinética de secagem. Além disso, foi comprovada a eficiência da secagem vibrofluidizada para valores de umidade da serragem maiores que $2 \mathrm{~kg} \mathrm{~kg}^{-1}$, com boa mobilidade do leito e qualidade de fluidização próxima de $90 \%$.

SOPONRONNARIT et al. (2000) desenvolveram, testaram e otimizaram um secador vibrofluidizado horizontal na secagem de arroz com casca (arroz paddy). Apresentaram as características operacionais, consumo de energia e análise de custos.

MARELLA et al. (1997) afirmaram que a combinação de agitação mecânica, centrífuga e vibração com a fluidização para garantir melhorias no produto e economia de energia tem se tornado uma prática comum atualmente. A pesquisa em secagem em leitos fluidizados é baseada em tentativa e erro, e poucos modelos matemáticos estão disponíveis na literatura. Assim, os autores propuseram modelo matemático de remoção de umidade em um SVF com os diferentes parâmetros que afetam essa remoção. A caseína foi utilizada como material de estudo, e a razão de umidade foi expressa como:

$$
\frac{X_{m}}{X_{o}}=f\left(\frac{E}{S_{L}}, V_{L}, \omega, d_{p}, m_{p, m}, m_{p, m s}, m_{p, 0}, \lambda, t\right)
$$

O modelo mostrou correlação muito boa e pode ser utilizado para o projeto de sistemas de leitos fluidizados para a secagem da caseína.

RAMESH \& SRINIVASA RAO (1996) estudaram a secagem de arroz cozido em um SVF. A escolha desse tipo de secador foi baseada na alta taxa de transferência de calor e massa, e do menor tempo de residência. Sendo o produto adesivo, é essencial o uso de agentes de agitação e movimentação durante a secagem do arroz cozido; assim, o SVF foi utilizado por combinar o movimento vibratório com o íntimo contato da partícula com o gás. Nesse estudo, a equação de Page (PAGE, 1949) foi utilizada para representar a secagem em camada delgada e mostrou-se adequada para explicar a secagem no SVF. Os autores concluíram que os resultados, segundo a equação de Page, foram similares aos obtidos em camada delgada, sendo o tempo de secagem 
facilmente determinado, uma vez determinados os parâmetros de secagem da equação de Page e conhecendo o conteúdo de água inicial e final (desejado) do produto a uma dada temperatura.

Utilizando esse mesmo secador, os autores também estudaram a aplicação de Redes Neurais Artificiais (RNA) para investigar a secagem do arroz cozido (RAMESH et al., 1996). As RNAs estão sendo utilizadas atualmente para resolver grande variedade de problemas em ciência e engenharia, dentre os quais a resolução de problemas de secagem de produtos alimentares. Em oposição às técnicas de modelagem (transferência simultânea de calor e massa, modelos cinéticos, modelos difusionais, modelos de fase e análises de regressão), a RNA pode suportar mais de duas variáveis para predizer dois ou mais parâmetros de saída. Como conclusão, a RNA mostrou ser ferramenta em potencial para desenvolver modelo de determinação de parâmetros de processos, especialmente quando os modelos existentes não podem suportar mais do que duas variáveis.

KAMIŃSKI et al. (1997) também se utilizaram da técnica de RNA para descrever a cinética de secagem de ervilhas em um SVF vertical de diâmetro de $200 \mathrm{~mm}$ e altura de $900 \mathrm{~mm}$. Os autores propuseram as funções de base radial (radial basis functions) como funções de transição nas RNAs. Boa concordância entre os dados experimentais e os resultados obtidos pela RNA foram conseguidos.

DUTTA \& DULLEA (1991) verificaram a utilização de vibração externa em leito fluidizado de um pó fino inorgânico coesivo com densidade de $3.900 \mathrm{~kg} \mathrm{~m}^{-3}$. Comprovaram o aumento na qualidade da fluidização, aumentando a expansão do leito, aumentando a perda de carga e diminuindo as perdas por elutriação.

JINESCU \& BALABAN (1982) utilizaram leito vibrofluidizado vertical para o estudo da cinética de secagem de poliestireno com alto conteúdo de umidade. Uma equação empírica para a taxa de secagem foi obtida para o poliestireno em termos dos seguintes fatores: diâmetro volumétrico das partículas, umidade livre inicial, índice de fluidização, razão entre a altura e o diâmetro da coluna, razão entre a aceleração vibracional e gravitacional, temperatura do agente de fluidização e natureza das partículas.

ZHU et al. (1999) estudaram a secagem de sementes de couve-chinesa em secador vibrofluidizado com radiação infravermelha. Para tanto, determinaram a distribuição de temperatura no leito de secagem por meio de equipamento de visão infravermelha, que possibilita uma análise térmica do que está acontecendo no leito. Além disso, também foram realizados experimentos para determinar a qualidade das sementes (germinação). Chegaram à conclusão de que a técnica é válida e que, utilizando um LVF, a temperatura crítica de secagem (temperatura na qual as sementes começam a sofrer danos) pode ser aumentada de $45^{\circ} \mathrm{C}$ para $48^{\circ} \mathrm{C}$.

Utilizando partículas de resina ion exchange, SUZUKI et al. (1980 a) estudaram as características de secagem no período de taxa constante em um secador vibrofluidizado vertical, em termos da taxa de circulação das partículas. Para os estudos, os autores assumiram uma mistura de partículas não-completa e dividiram o leito de secagem em várias seções, onde, em cada uma, a taxa de circulação das partículas foi adotada como parâmetro para o cálculo da taxa de secagem e o conteúdo de umidade. Concluíram que a influência da vibração na uniformidade do conteúdo de umidade é significativa apenas para velocidade do ar menores que $\mathrm{u}_{\mathrm{mf}}$, além de, também, apresentar dependência da intensidade vibracional e da altura do leito.

Em outro artigo, SUZUKI et al. (1980 b) estudaram as características de secagem no período de secagem decrescente de partículas de resina ion exchange (Amberlite IR-120 B). Afirmaram que, usualmente, é assumido que grande parte do processo de secagem de partículas pequenas pode ser analisada somente no período constante, devido ao baixo conteúdo crítico de umidade dessas. Mas em materiais com alto conteúdo crítico de umidade, o período de secagem à taxa decrescente tem de ser levado em conta. No artigo, os autores dividiram o período em dois estágios e analisaram o processo de secagem utilizando o modelo do artigo anterior. A distribuição do conteúdo de umidade no leito depende da taxa de circulação de partículas no primeiro período 
decrescente de secagem, e foi similar ao valor da taxa constante. Contudo, para o segundo período decrescente, esse valor diminuiu abruptamente.

Esses resultados mostram que o leito pode ser seco com conteúdo uniforme de umidade, em uma apropriada intensidade de vibração, mesmo quando a velocidade do ar é menor do que a mínima de fluidização. Mas a maioria dos pós e dos sólidos granulares tem a tendência de aglomerar quando são úmidos ou reumidificados. Assim, os autores do artigo anterior estudaram a uniformidade do conteúdo de umidade em um leito de materiais aglomerativos em termos da taxa de circulação de partículas (SUZUKI et al., 1980 c). Concluíram que, mesmo para um estado muito agregativo, as partículas tiveram boa circulação e mistura, e o processo de secagem pôde ser realizado com um conteúdo de umidade uniforme no leito, em apropriadas condições de vibração.

BROD et al. (1998) estudaram a secagem de cenoura cortada em cubos utilizando secador vibrofluidizado. Concluíram que a secagem da cenoura procedeu-se em todas as dimensões e que a difusividade efetiva aumenta com o aumento da amplitude de vibração e da temperatura de secagem.

\section{CONCLUSÕES}

Secadores de leitos vibrofluidizados são opção para a secagem de materiais granulares, aglomerados, pastosos e pós.

Apesar da literatura vasta encontrada, ainda são necessárias pesquisas futuras para a obtenção de mais dados que possam auxiliar nos procedimentos para projetistas.

\section{AGRADECIMENTOS}

À Fundação de Amparo à Pesquisa do Estado de São Paulo (FAPESP), ao Conselho Nacional de Desenvolvimento Científico e Tecnológico (CNPq), à Coordenação de Aperfeiçoamento de Pessoal de Nível Superior (CAPES) e à Universidade Estadual de Campinas (UNICAMP).

\section{NOMENCLATURA}

A - amplitude da vibração, m;

$\mathrm{c}_{\mathrm{p}}$ - capacidade térmica a pressão constante, $\mathrm{J} /(\mathrm{kg} \mathrm{K})$;

cf - coeficiente fenomenológico;

d - diâmetro, m;

$\mathrm{D}$ - difusividade, $\mathrm{m}^{2} \mathrm{~s}^{-1}$;

$\mathrm{d}_{\mathrm{c}}$ - densidade de carga, $\mathrm{kg} \mathrm{m}^{-2}$;

$\mathrm{E}$ - energia total do ar, $\mathrm{J}$;

$\mathrm{f}$ - frequiência de vibração, $\mathrm{s}^{-1}$;

$\mathrm{g}$ - aceleração da gravidade, $\mathrm{m} \mathrm{s}^{-2}$;

$\mathrm{H}$ - altura do leito, $\mathrm{m}$;

$\mathrm{h}$ - coeficiente convectivo de transferência de calor, $\mathrm{W}\left(\mathrm{m}^{2} \mathrm{~K}\right)$;

$\mathrm{h}_{\mathrm{gp}} \mathrm{S}$ - coeficiente volumétrico de transferência de calor, $\mathrm{W}\left(\mathrm{m}^{3} \mathrm{~K}\right)$;

if - índice de fluidização;

$\mathrm{k}_{\mathrm{y}} \mathrm{s}$ - coeficiente volumétrico de transferência de massa, $\mathrm{kg}_{\text {arseco }}\left(\mathrm{s} \mathrm{m}^{3}\right)$;

$\mathrm{k}_{\mathrm{y}}$ - coeficiente de transferência de massa, $\mathrm{kg}\left(\mathrm{m}^{2} \mathrm{~s}\right)$;

L - comprimento característico, $\mathrm{m}$;

$\mathrm{m}$ - massa, kg;

$\dot{m}$ - vazão mássica, $\mathrm{kg} \mathrm{s}^{-1}$;

$\mathrm{q}$ - fluxo de calor por área, $\mathrm{W} \mathrm{m}^{-2}$;

$\mathrm{s}$ - área das partículas por unidade de volume do leito, $\mathrm{m}^{2} \mathrm{~m}^{-3}$;

$\mathrm{S}$ - área, $\mathrm{m}^{2}$

$\mathrm{Sm}$ - área superficial por massa de partícula, $\mathrm{m}^{2} \mathrm{~kg}^{-1}$;

$\mathrm{t}$ - tempo, s; 
$\mathrm{T}$ - temperatura, ${ }^{\circ} \mathrm{C}$ ou $\mathrm{K}$;

$\mathrm{u}$ - velocidade, $\mathrm{m} \mathrm{s}^{-1}$;

$\mathrm{u}^{*}$ - velocidade superficial aparente, $\mathrm{m} \mathrm{h}^{-1}$;

$\mathrm{V}$ - volume, $\mathrm{m}^{-3}$;

y - direção de difusão, m;

$\mathrm{X}$ - conteúdo de umidade, $\mathrm{kg}_{\mathrm{H} 2 \mathrm{O}} / \mathrm{kg}_{\mathrm{ms}}$, e

$\mathrm{W}$ - umidade do ar, $\mathrm{kg}_{\mathrm{H} 2 \mathrm{O}} / \mathrm{kg}_{\text {ar seco. }}$.

\section{Letras gregas}

$\theta=\mathrm{t} / \overline{\mathrm{t}}$ - tempo relativo;

$\lambda$ - calor latente de vaporização da água, $\mathrm{J} \mathrm{kg}^{-1}$;

$\rho$ - densidade, $\mathrm{kg} \mathrm{m}^{-3}$;

$\Gamma$ - intensidade de vibração, adimensional;

$\varepsilon$ - porosidade, adimensional;

$\delta$ - parâmetro característico da secagem;

$\omega$ - freqüuência angular de vibração, $\mathrm{s}^{-1}$;

$v$ - viscosidade cinemática, $\mathrm{m}^{2} \mathrm{~s}^{-1}$;

$\mu$ - viscosidade dinâmica, $\mathrm{Pa}$ s, e

$\varphi$ - inclinação do secador, graus.

\section{Subscritos}

1 - primeiro período de secagem;

2 - segundo período de secagem;

0 - inicial;

cr - crítico;

cte - constante;

eq - equilíbrio;

ev - evaporada;

f - final;

g - gás;

gp - gás-partícula;

$\mathrm{H}_{2} \mathrm{O}$ - água;

int - condições na interface sólido-gás;

L - leito;

$\mathrm{m}$ - média;

mf - mínima de fluidização;

ml - média logarítmica;

ms - massa seca;

mv - médio volumétrico;

p - partícula;

r - radiativo;

s - sólido;

vib - vibração, e

$\mathrm{v}$ - volumétrico.

\section{Adimensionais}

Parâmetro adimensional de vibração, $\Gamma=\frac{\mathrm{A} \omega^{2}}{\mathrm{~g}}$;

Número de Reynolds, $\operatorname{Re}=\frac{\mathrm{d} \rho \mathrm{u}}{\mu}$; 
Número de Sherwood, $S h=\frac{k_{y} d_{p}}{\rho D}$;

Número de Schmidt, $\mathrm{Sc}=\frac{\mu_{\mathrm{g}}}{\rho_{\mathrm{g}} \mathrm{D}}, \mathrm{e}$

Número de Spalding, $\mathrm{Sp}=\frac{\mathrm{c}_{\mathrm{PH}_{\mathrm{O}} \mathrm{O}}\left(\mathrm{T}_{\mathrm{g}}-\mathrm{T}_{\mathrm{s}}\right)}{\lambda}$.

\section{REFERÊNCIAS}

BAHU, R.E. Fluidized bed dryer scale-up. Drying Technology, New York, v.12, n.1, p.329-39, 1994.

BANZATTO, L.L.; ZACTITI, E.M.; LIMAVERDE, J.R.; FINZER, J.R.D. Secador de bandejas vibradas: controle do escoamento dos sólidos aplicando vibrações em sentidos opostos. In: CONGRESSO BRASILEIRO DE SISTEMAS PARTICULADOS - ENEMP, 27., 1999, Campos do Jordão. Anais... São Paulo: Editora da USP, 2000. p. 563-9.

BORDE, I.; DUKHOVNY, M.; ELPERIN, T.; KATZ, V. Investigation of drying in a multistage dryer with a vibrofluidized bed. In: INTERNATIONAL DRYING SYMPOSIUM (IDS'96), 10., 1996, Cracóvia-Polônia. Proceedings... Lodz-Polônia: Lodz Technical University, 1996. v.A, p.398-404.

BORDE, I.; DUKHOVNY, M.; ELPERIN, T. Heat and mass transfer in a moving vibrofluidized granular bed. Powder Handling \& Processing, Clausthal Zellerfeld, v.9, n.4, p. 311-14, 1997.

BROD, F.P.R.; ALONSO, L.F.T.; ROSA, R.H.C.; MINAGAWA, F.K.; PARK, K.J. Carrot (Daucus carota L.) drying in a vibro-fluidized dryer. In: INTERNATIONAL DRYING SYMPOSIUM (IDS'98), 11., 1998, Halkidiki, Grécia. Proceedings... Thessaloniki-Grécia: Ziti Editions, 1998. v.B, p.1237-43.

CANELLAS NETO, A.A.; FREIRE, J.T. Estudo do coeficiente de transferência de massa em leito vibrofluidizado. In: CONGRESSO BRASILEIRO DE SISTEMAS PARTICULADOS (ENEMP). 27., 1999, Campos do Jordão. Anais... São Paulo: Editora da USP, 2000. p. 307-14.

CARDOSO, C.S.B.; KIECKBUSCH, T.G. Secagem de fatias de banana em leito vibrofluidizado a altas temperaturas por curto tempo. In: CONGRESSO BRASILEIRO DE SISTEMAS

PARTICULADOS - ENEMP, 26., 1998, Teresópolis. Anais... Rio de Janeiro: DTQ-UFRRJ, 1998. v.II, p.385-92.

DANIELSEN, S.; HOVMAND, S. Drying of granulated product in a vibrated fluid be. In: MUJUMDAR, A.S. (Org.). Drying 80. New York: Hemisphere Publishing, 1980. v.1, p.194-9.

DONG, Z.X.; PAN, Y.K.; DENG, W.Y.; WEI, Z.; MUJUMDAR, A.S. Effect of vibration on the drying rate during the falling rate period. Drying Technology, New York, v.9, n.3, p.723-33, 1991.

DUTTA, A.; DULLEA, L.V. Effects of external vibration and the addition of fibers on the fluidization of a fine powder. AIChE Symposium Series - Advances in Fluidized Systems, New York, v.87, n.281, p.38-46, 1991.

ECCLES, E.R.A.; MUJUMDAR, A.S. Bubble phenomena in aerated vibrated beds of small particles. Drying Technology, New York, v.15, n.1, p.92-116, 1997.

ERDÉSZ, K. Hydrodynamic studies on vibrated fluidized beds. Powder Handling \& Processing, Germany, v.2, n.4, p.327-39, 1990.

ERDÉSZ, K.; MUJUMDAR, A.S. Bibliography of literature on fundamentals and applications of vibration in particle processing. Drying Technology, New York, v.5, n.2, p.311-32, 1987.

ERDÉSZ, K.; ORMÓS, Z. Granulation in vibro fluidized bed. In: MUJUMDAR, A.S. Drying of solids: recent international developments. New York: Halsted Press, 1986. p.54-67. 
FINZER, J.R.D. Secagem de fatias de cebola em leito vibrofluidizado. 1984. 134 f. Dissertação (Mestrado em Engenharia de Alimentos) - Faculdade de Engenharia de Alimentos, UNICAMP, Campinas, 1984.

FINZER, J.R.D.; KIECKBUSCH, T.G. Secagem em sistemas com vibração. In: FREIRE, J.T.; SARTORI, D.J.M. Tópicos especiais em secagem. São Carlos: UFSCar, v.1, 1992 p. 87-127.

GARIM, M.M.; FREIRE, J.T. Coeficiente de transferência de massa de uma esfera para um leito vibrofluidizado. In: ENCONTRO SOBRE ESCOAMENTO EM MEIOS POROSOS, 21., 1993, Ouro Preto. Anais... Belo Horizonte: UFMG, 1994a. v. II, p.408-19.

GARIM, M.M.; FREIRE, J.T. Análise da influência da atrição no coeficiente de transferência de massa de um corpo submerso para um leito vibrofluidizado. In: ENCONTRO SOBRE ESCOAMENTO EM MEIOS POROSOS, 22., 1994, Florianópolis- SC. Anais... Florianópolis: DEQ/UFSC, 1994b, v. I, p.147-154.

GUPTA, R.; MUJUMDAR, A.S. Aerodynamics and thermal characteristics of vibrated fluid beds a review. In: MUJUMDAR, A.S. (Org.). Drying 80. New York: Hemisphere Publishing, v.1, 1980 a. p.141-150.

GUPTA, R.; MUJUMDAR, A.S. Aerodynamics of a vibrated fluid bed. The Canadian Journal of Chemical Engineering, Ottawa, v.58, n.3, p.332-8, 1980 b.

HAN, W.; MAI, B.; GU, T. Residence time distribution and drying characteristics of a continuous vibro-fluidized bed. Drying Technology, New York, v.9, n.1, p.159-81, 1991.

HASATANI, M.; ARAI, N.; HORI, K. Drying of granular particles in a multistage inclined fluidized-bed with mechanical vibration. Drying Technology, New York, v.3, n.1, p.39-62, 1985.

HASATANI, M.; ITAYA, Y.; MIURA, K. Drying of granular materials in an inclined vibrated fluidized bed by combined radiative and convective heating. Drying Technology, New York, v.9, n.2, p.349-66, 1991.

HOVMAND, S. Fluidized bed drying. In: MUJUMDAR, A.S. Handbook of industrial drying. New York: Marcel Dekker, 1987. cap. 6, p.165-225.

JINESCU, G.; BALABAN, C. Drying of granulated polymers in vibro-fluidized bed. In: INTERNATIONAL DRYING SYMPOSIUM, 3., 1982, Birmingham. Proceedings... England: Drying Research, 1982. v.2, p.124-9.

KAMIŃSKI, W.; STAWCZYK, J.; TOMCZAK, E. Presentation of drying kinetics in a fluidized bed by means of radial basis functions. Drying Technology, New York, v.15, n.6-8, p.1753-62, 1997.

KUDRA, T. Novel drying technologies for particulates, slurries and pastes. In: MUJUMDAR, A.S. (Ed.). Drying 92. Great Britain: Elsevier Science Publishers, 1992. v.B, p.224-39.

MARELLA, C.; PATEL, S.; SHAH, U.S. A mathematical model for vibrofluidized beds for drying casein. Journal of Food Science and Technology, Mysore, v.34, n.2, p.153-4, 1997.

MENEZES, E.A.; FINZER, J.R.D.; LIMAVERDE, J.R. Desenvolvimento de um secador de bandejas vibradas. In: CONGRESSO BRASILEIRO DE SISTEMAS PARTICULADOS ENEMP, 23., 1995, Maringá. Anais... [s.1.: s.n.], 1995. v.1, p.285-97.

MENEZES, E.A.; CARILLI, A.; FINZER, J.R.D.; LIMAVERDE, J.R. Secagem de grãos de café em sistema de múltiplas bandejas vibradas. In: CONGRESSO BRASILEIRO DE SISTEMAS PARTICULADOS - ENEMP, 24., 1996, Uberlândia. Anais... Uberlândia: UFU, 1996.a. v.1, p.24752.

MENEZES, E.A.; CARILLI, A.; FINZER, J.R.D.; LIMAVERDE, J.R. Escoamento de grãos de café em sistemas de múltiplas bandejas vibradas. In: CONGRESSO BRASILEIRO DE 
SISTEMAS PARTICULADOS - ENEMP, 24., 1996, Uberlândia. Anais... Uberlândia: UFU, 1996b. v.2, p.763-8.

MORENO, R.; RÍOS, R.; CALBUCURA, H. Batch vibrating fluid dryer for sawdust particles: experimental results. Drying Technology, New York, v.18, n.7, p.1481-93. 2000.

MROWIEC, M.; CIESIELCZYK, W. Fluidized-bed dryers for paste materials. International Chemical Engineering, New York, v.17, n.2, p.373-9, 1977.

MUJUMDAR, A.S. Drying technologies of the future. Drying Technology, New York, v.9, n.2, p.325-47, 1991.

MUJUNDAR, A.S.; ERDESZ, K. Applications of vibration techniques for drying and agglomeration in food processing. Drying Technology, New York, v.6, n.2, p.255-74. 1988.

NILSSON, L.; WIMMERSTEDT, R. Drying in longitudinal-flow vibrating fluid-beds - Pilot plant experiments and model simulations. Drying Technology, New York, v.5, n.3, p.337-61, 1987.

NOVY, M.G.; KIECKBUSCH, T.G. Secagem de alimentos líquidos em leito vibrofluidizado contendo inertes. In: ENCONTRO SOBRE ESCOAMENTO EM MEIOS POROSOS - ENEMP, 15., 1987, Uberlândia. Anais... Uberlândia: CETECUFU, 1987. v.II, p.430-40.

PAGE, G.E. Factors influencing the maximum of air drying shelled corn in thin layer. 1949. Thesis (M.Sc.) - Purdue University, Indiana, 1949.

PAKOWSKI, Z.; MUJUMDAR, A.S.; STRUMILLO, C. Theory and application of vibrated beds and vibrated fluid beds for drying process. In: MUJUMDAR, A. S. (ed.) Advances in drying. New York: Hemisphere Publishing Corporation, 1984. v.3, cap.7, p.245-306.

PAN, Y.K.; PANG, J.Z.; LI, Z.Y.; MUJUMDAR, A.S.; KUDRA, T. Drying of photosynthetic bacteria in a vibrated fluid bed of solid carriers. Drying Technology, New York, v.13, n.1-2, p.395404, 1995.

PAN, Y.K.; LI, Z.Y.; MUJUMDAR, A.S.; KUDRA, T. Drying of a root crop in vibrofluidized beds. Drying Technology, New York, v. 15, n. 1, p. 225-223, 1997 a.

PAN, Y.K.; WU, H.; LI, Z.Y.; MUJUMDAR, A.S.; KUDRA, T. Effect of a tempering period on drying of carrot in a vibro-fluidized bed. Drying Technology, New York, v.15, n.6-8, p. 2037-43, 1997 b.

PAN, Y.K.; ZHAO, L.J.; DONG, Z.X.; MUJUMDAR, A.S.; KUDRA, T. Intermittent drying of carrot in a vibrated fluid bed: Effect on product quality. Drying Technology, New York, v.17, n.10, p. 2323-40, 1999a.

PAN, Y.K.; ZHAO, L.J.; HU, W.B. The effect of tempering-intermittent drying on quality and energy of plant materials. Drying Technology, New York, v.17, n.9, p.1795-1812, 1999 b.

RAMESH, M.N.; KUMAR, M.A.; SRINIVASA RAO, R.M. Application of artificial neural networks to investigate the drying of cooked rice. Journal of Food Process Engineering, Connecticut, v.19, n.3, p.321-9, 1996.

RAMESH, M.N.; SRINIVASA RAO, R.M. Drying studies of cooked rice in a vibrofluidized bed drier. Journal of Food Engineering, Kidlington, v.27, n.4, p.389-96, 1996.

RINGER, D.U.; MUJUMDAR, A.S. Analysis of aerodynamics and heat-transfer in vibrofluidized beds. Drying Technology, New York, v.2, n.4, p.449-70, 1983-84.

ROMANKOV, P.G. Drying. In: DAVIDISON, J.F.; HARRISON, D. Fluidization. London: Academic Press, 1971. p.569-598.

ROWE, P.N. Experimental properties of bubbles. In: DAVIDISON, J.F.; HARRISON, D.

Fluidization. London: Academic Press, 1971. p.121-91. 
RYZHKOV, A.F. Hydrodynamics and mass heat-transfer in vibrofluidized dispersed media (Thesis Summary). Drying Technology, New York, v.10, n.1, p.271-4, 1992.

SANZ, F.J.; FITO, P.J.; REQUENI, V. Secado de salvado de arroz em lecho vibrofluidizado. II. Estúdio de la cinética Del secado em el período de velocidad de secado constante. Revista de Agroquimica y Tecnologia de Alimentos, Valencia, v.17, n.1, p.131-9, 1977.

SHAH, R.M.; GOYEL, S.K. Drying characteristics of tea fluidized on a vibrating bed (part II) handling of dust grades \& its impacts on quality. Drying Technology, New York, v.13, n.5-7, p.1523-41, 1995.

SHILTON, N.C.; NIRANJAN, K. Fluidization and its applications to food processing. Food Structure, Chicago, v.12, n.2, p.199-215, 1993.

SOPONRONNARIT, S.; WETCHACAMA, S.; TRUTASSANAWIN, S.; JARIYATONTIVAIT. W. Design, testing and optimization of vibro-fluidized bed paddy dryer. In: INTERNATIONAL DRYING SYMPOSIUM IDS' 2000, 12., 2000, Noordwijkerhout, Holanda. Proceedings... Amsterdam: Elsevier Science, 2000. 1 CD-ROM (paper $n^{\circ} 225$ ).

STAKIĆ, M.B. Heat and mass transfer during processes of powdery and fine-grained materials by means of vibro-fluidization (Thesis Summary). Drying Technology, New York, v.13, n.8\&9, p.2241-2, 1995.

STRUMILLO, C.; PAKOWSKI, Z. Drying of granular products in vibrofluidized beds. In: MUJUNDAR, A. S. (Ed.). Drying '80: Developments in Drying. Washington: Hemisphere Publishing, v.1, 1980. p.211-26.

SUZUKI, K.; HOSAKA, H.; YAMAZAKI, R.; JIMBO, G. Drying characteristics of particles in a constant drying rate period in vibro-fluidized bed. Journal of Chemical Engineering of Japan, Tokyo, v.13, n.2, p.117-22, 1980 a.

SUZUKI, K.; HOSAKA, H.; YAMAZAKI, R.; JIMBO, G. Some investigations of falling rate period of vibro-fluidized bed drying. Journal of Chemical Engineering of Japan, Tokyo, v.13, n.6, p. $493-5,1980$ b.

SUZUKI, K.; HOSAKA, H.; YAMAZAKI, R.; JIMBO, G. Characteristics of vibro-fluidized bed for drying of wetted and agglomerated particles. Journal of Chemical Engineering of Japan, Tokyo, v.13, n.6, p.495-8, 1980 c.

SZALAY, A.; ERDÉSZ, K.; ZAGROUBA, F.; ROQUES, M.A. Principles for hydro dynamical and geometrical design of vibrated bed driers. Drying Technology, New York, v.13, n.5-7, p.124960, 1995.

ZHU, K.; LI, X.; CHU, Z.; YANG, J. The thermo-image experimental study for the optimization of seeds drying. Drying Technology, New York, v.17, n.9, p.1935-45, 1999. 